\title{
The Process of Urbanisation in Pakistan, 1951-81
}

\author{
G. M. ARIF and SABIHA IBRAHIM
}

\section{INTRODUCTION}

The current level of urbanisation in Pakistan, approximately 33 percent in 1998, is not high by global standards. ${ }^{1}$ But it is commonly linked with unemployment, underemployment, shortage of housing, transport and other infrastructure like water supply and sewerage. Compared to other areas of population dynamics, such as fertility and mortality, studies in the field of urbanisation and internal migration in Pakistan are rather limited. During the last three decades hardly half a dozen studies could be added in the field of urbanisation. These studies are primarily based on data generated by the different censuses. ${ }^{2}$ After the 1979 Population Labour Force and Migration (PLM) Survey, no nationally representative survey addressing the issue of urbanisation and internal migration could be carried out. Even regional studies could not be conducted during the last two decades. ${ }^{3}$

The present study is designed to utilise the 1998 census data to investigate urban population growth, pace (or tempo) of urbanisation and components of urban growth for the period of 1981-98. The study has also attempted to analyse

G. M. Arif and Sabiha Ibrahim are Senior Research Demographer, and Research Demographer, respectively, at the Pakistan Institute of Development Economics, Islamabad.

Authors' Note: We are thankful to Dr M. Irfan and Dr Naushin Mahmood, Joint Director and Chief of Research at PIDE, respectively, for their encouragement and guidance to complete this study. We are also grateful to Mr Rafiq Ahmed, Senior Systems Analyst, PIDE, for his valuable assistance in the data analysis. Assistance provided for data entry by Mr Wasim Ahmed, Computer Operator, and $\mathrm{Mr}$ Abdul Sattar, Research Associate, PIDE, is highly appreciated.

${ }^{1}$ This level, however, is the highest among the South Asian countries. In the early 1990s, the level of urbanisation was 17 percent in Bangladesh, 27 percent in India, 22 percent in Sri Lanka, and only 9 percent in Nepal [Ertur (1994)].

${ }^{2}$ For example, Helbock (1975); Abbasi (1987); Rukanuddin (1989); Pakistan (GOP) (1989); Kiani and Siyal (1991); Butt (1996).

${ }^{3}$ In the late 1970s, several studies based on sample surveys, which looked at reasons for migration to large cities, namely Gujranwala, Peshawar, Quetta, Karachi and Faisalabad, were carried out. However, Khan's study is an exception [Khan (1996)]. He has recently examined the impact of urbanisation on economic integration focusing on Peshawar. 
characteristics of urban system by examining the concentration of urbanisation. However, because of the data scarcity, this study has not explored some other important aspects of urbanisation, such as its determinants and consequences. At the availability of the complete census data, these aspects would be examined in the future.

The next section of the paper reports the data sources and limitations, followed by urbanisation and growth of urban population in Section 3. Tempo of urbanisation and components of growth are discussed in Sections 4 and 5. The characteristics of urban system are examined in Section 6. Summary and policy implications are presented in the final section.

\section{DATA SOURCES AND LIMITATIONS}

This study is primarily based on the provisional results of the 1998 census. The trends and patterns of urbanisation estimated from these provisional results have been compared with previous studies based on the 1951, 1961, 1972, and 1981 censuses. Information that is provided in the provisional results of the 1998 census is limited to 'number of households' and 'population by gender' for provinces, districts, tehsils/talukas and urban settlements. These statistics are not sufficient to carry out a comprehensive study of urbanisation, though they do facilitate to estimate the recent trends and patterns of urbanisation. The present study has used the provincial and district level data to examine urban population growth and tempo of urbanisation for the 1981-98 period. Data for different urban localities have been used to examine the components of urban growth and characteristics of urban system.

With respect to urban population, there seems to be three major limitations of the 1998 census. $^{4}$ These limitations might have depressed its share in the total population of the country. First, immigrant population has not been included in the provisional results of the census. A large number of Afghan refugees and illegal immigrants are concentrated in Karachi and Peshawar and Quetta. This exclusion has certainly depressed the share of urban population. Second, there has always been a possibility of double counting of internal rural migrants at the places of their origin and destination. But in view of the strict measures taken by the Population Census Organisation to avoid duplication, many urban persons might have themselves enumerated in the rural areas of their origin thus increasing rural population and decreasing urban dwellers [Jillani (1998)]. Third, there are some fears that communities adjacent to cities were counted in the 1998 census as rural as compared to the 1981 census when they were treated as urban. This might have inflated the rural population and depressed the urban count.

${ }^{4}$ For the major limitations of data generated by the 1951, 1961,1972 and 1981 censuses, see Abbasi (1987). 
However, it is the definition of 'urban' used in the census, which affects the most not only urban areas, but also the size of the total population. The definition of an urban area adopted in the first three censuses 1951, 1961 and 1972, was more or less same. A city or town was regarded as an urban area if it had a minimum of 5,000 inhabitants. The municipal and town committees were also treated an urban area if they had fewer than 5,000 inhabitants. There also existed the provision to include any other area having urban characteristics. The definition of 'urban' was changed in 1981 census by replacing the size-specified definition with an administrative criterion. The definition of 'urban' used in the 1998 census is also based on this criterion. This similarity in definition makes the data generated by the two latest censuses comparable. ${ }^{5}$

\section{URBANISATION AND URBAN GROWTH, ${ }^{6} 1951-1998$}

The population of Pakistan, which was estimated at about 33 million at the time of Independence in 1947, increased to 43 million in 1961. During the next 20 years it almost doubled and reached to 84 million in 1981. The 1998 census counted the population of Pakistan at about 131 million, showing an increase of more than 46 million persons during the 1981-98 period [Pakistan (1998)]. Data showing the evolution of the country's urbanisation process and urban growth are presented in Table 1. In terms of absolute numbers, the population living in urban areas increased from 6 million in 1951 to about 43 million in 1998. The 1998 urban population exceeded the total population of the country in 1951. As noted earlier, the share of urban population in the total population increased from 18 percent in 1951 to about 33 percent in $1998 .^{7}$

${ }^{5}$ Jillani (1998) has criticised this criterion. He opines that the administrative division-based definition is inferior to the criterion based on urban characteristics for planning and socio-economic analysis. He argues that had the latter criterion been adopted, urban population in Pakistan would have counted as 50 percent of the total population.

${ }^{6}$ Urbanisation refers to the rise in the proportion of total population living in urban areas. Urban growth refers to the increasing population living in urban areas. The two are quite distinct; urbanisation can take place over a range of urban population growth rates from high to low [Jones (1991)].

${ }^{7}$ This current level of urbanisation is much less than the level projected by different institutions and students of urbanisation during the last two and half a decades. For example, in the early 1970s, Burki estimated that by 2001 the nation's urban population will number 86 million and will make up nearly two-thirds of Pakistan's total population [Burki (1973)]. The United Nation's projection made in the 1980s and early 1990s showed the level of urbanisation around 40 percent by 2001 [UN (1992)]. Even the Planning Commission's working group on urbanisation for the Ninth Five Year Plan estimated the share of urban dwellers at about 35 percent in 1993 [Butt (1996)]. 
Table 1

Size, Level, and Growth of Pakistan’s Urban Population, 1951-1998

\begin{tabular}{lccccc}
\hline Population (000)/ & \multicolumn{5}{c}{ Census Years } \\
\cline { 2 - 6 }$\quad$ Urban Growth & 1951 & 1961 & 1972 & 1981 & 1998 \\
\hline Total Population & 33780 & 42880 & 65309 & 84253 & 130580 \\
Urban Population & 6019 & 9655 & 16593 & 23827 & 42458 \\
Share of Urban Population in Total & & & & & 32.5 \\
$\quad$ Population (\%) & 17.8 & 22.5 & 25.0 & 28.3 & 3.5 \\
$\quad$ Intercensal Annual Urban Growth Rate (\%) & - & 4.9 & 4.8 & 4.4 & 2.2 \\
Intercensal Annual Rural Growth Rate (\%) & - & 1.8 & 3.4 & 2.6 & 1.4 \\
Ratio of Urban to Rural Growth* & - & 3.0 & 1.6 & 1.8 & \\
\hline
\end{tabular}

Source: Abbasi (1987); Pakistan (1998).

* Refers to intercensal growth rates.

A look at the data presented in Table 1 indicates that the average annual growth rate of urban population declined monitically from 4.9 percent for the intercensal period of 1951-61 to 3.5 percent for the 1981-98 period. But the rural growth rate fluctuated substantially between 1951 and 1998. It increased from 1.8 percent for the intercensal period of 1951-61 to 3.4 percent for the next intercensal interval, 1961-72. It dropped to 2.6 for the 1972-81 period, and declined further to 2.2 percent during 1981-98. Because of these fluctuations in the rural growth rates, the ratio of urban to rural growth fluctuated as well during the four-intercensal intervals (Table 1). However, despite these fluctuations, the ratio has declined from 3 in 1961 to 1.4 in 1998. Consequently the degree or level of urbanisation has increased overtime but, as noted earlier (footnote 8), this increase is not as rapid as was being projected mainly because of a continuous decline in the annual urban growth rate. ${ }^{8}$

Data showing the evolution of the country's urbanisation process and urban growth at the province level are presented in Table 2. In 1998 Sindh was the most urbanised province with 49 percent of total provincial population living in urban areas. The least urbanised province with only 17 percent of provincial population living in urban areas was the NWFP. The shares of urban population in total population of Punjab and Balochistan were respectively 31 and 23 percent. Urban population of Balochistan grew at the fastest rate not only between 1972 and 1981 but also during 1981-98. Butt (1996) attributed the rapid rate of urbanisation in Balochistan to the major increase in public sector employment due to the big increase in provincial government expenditure during the 1980s. It is worth noting that urban population of Islamabad grew at the rate of about 6 percent per annum during 1981-98. However, this rate is about half of the rate at which Islamabad's urban population grew between 1972 and 1981.

${ }^{8}$ For reasons of this decline, see next section, dealing with the tempo of urbanisation. 
Table 2

Size, Level, and Growth of Urban Population, By Province, 1951-1998

\begin{tabular}{|c|c|c|c|c|c|}
\hline \multirow{2}{*}{$\begin{array}{l}\text { Population (000)/ } \\
\text { Urban Growth }\end{array}$} & \multicolumn{5}{|c|}{ Census Year } \\
\hline & 1951 & 1961 & 1972 & 1981 & 1998 \\
\hline \multicolumn{6}{|l|}{ Punjab } \\
\hline Total Population & 20648 & 25463 & 37611 & 47292 & 72585 \\
\hline Urban Population & 3587 & 5461 & 9183 & 13052 & 22699 \\
\hline Urban Population (\%) & 17.4 & 21.4 & 24.4 & 27.6 & 31.3 \\
\hline Intercensal Annual Urban Growth Rate (\%) & - & 4.3 & 4.5 & 4.2 & 3.3 \\
\hline Ratio of Urban to Rural Growth* & - & 3.0 & 1.6 & 2.3 & 1.6 \\
\hline \multicolumn{6}{|l|}{ Sindh } \\
\hline Total Population & 6054 & 8374 & 14158 & 19029 & 29991 \\
\hline Urban Population & 1768 & 3169 & 5726 & 8243 & 14662 \\
\hline Urban Population (\%) & 29.2 & 37.8 & 40.4 & 43.3 & 48.9 \\
\hline Intercensal Annual Urban Growth Rate (\%) & - & 6.0 & 5.2 & 4.4 & 3.4 \\
\hline Ratio of Urban to Rural Growth* & - & 4.1 & 1.3 & 1.6 & 1.8 \\
\hline \multicolumn{6}{|l|}{ NWFP } \\
\hline Total Population & 4587 & 5752 & 8392 & 11061 & 17555 \\
\hline Urban Population & 502 & 758 & 1196 & 1666 & 2973 \\
\hline Urban Population (\%) & 10.9 & 13.2 & 14.3 & 15.1 & 16.9 \\
\hline Intercensal Annual Urban Growth Rate (\%) & - & 4.2 & 4.0 & 4.0 & 3.5 \\
\hline Ratio of Urban to Rural Growth* & - & 2.2 & 1.3 & 2.0 & 1.4 \\
\hline \multicolumn{6}{|l|}{ Balochistan } \\
\hline Total Population & 1187 & 1385 & 2432 & 4332 & 6511 \\
\hline Urban Population & 133 & 228 & 400 & 677 & 1516 \\
\hline Urban Population (\%) & 11.2 & 16.5 & 16.4 & 15.6 & 23.3 \\
\hline Intercensal Annual Urban Growth Rate (\%) & - & 5.5 & 4.9 & 6.4 & 4.9 \\
\hline Ratio of Urban to Rural Growth* & - & 4.6 & 0.9 & 1.0 & 3.4 \\
\hline \multicolumn{6}{|l|}{ Islamabad } \\
\hline Total Population & 94 & 119 & 234 & 340 & 799 \\
\hline Urban Population & - & - & 77 & 204 & 524 \\
\hline Urban Population (\%) & - & - & 32.9 & 60.0 & 65.6 \\
\hline Intercensal Annual Urban Growth Rate (\%) & - & - & - & 11.4 & 5.7 \\
\hline Ratio of Urban to Rural Growth* & - & - & - & -11.9 & 4.3 \\
\hline
\end{tabular}

Source: Pakistan (1951, n.d., 1984, and 1998). 
Table 2 reveals another important dimension of the process of urbanisation in Pakistan. Urban population of three provinces, Punjab, Sindh and NWFP grew at the same rate (around 3.5 percent per annum) between 1981 and 1998. There was also not much difference in urban growth of these provinces for the period of 1972-81. However, differences did exist in this growth across these provinces during the 1950s and 1960s, when Sindh was the fastest growing province. In view of relatively more rapid decline in the growth of urban population of Sindh, it has recently been argued that the large cities of Sindh, particularly Karachi and Hyderabad, have lost their dynamism due to the dislocation of economic activities caused by the troubled law and order situation in these cities during the last one and a half decade [Butt (1996)]. This argument seems to be only partially correct because it is not only Sindh, which has experienced a decline in the annual rate of urban growth overtime, but Punjab and NWFP followed the same path (Table 2).

These changes in the urban growth across the regions overtime can be explained in another way. There seems to be an increasing convergence in urban population growth rates not only across the four provinces but also across the cities. Figure 1 where the average annual growth rates of both 10 largest cities and other urban centres (excluding the 10 largest cities) were plotted for the 1951-98 period shows that small and medium-sized cities have grown rapidly during the two decades. The curve showing the average annual growth rate of the other urban centres crossed over the curve indicating the growth of the 10 largest cities in 1972. Since then the growth of the former has been higher than the growth of the latter. However, the gap between the two curves has narrowed over time, suggesting a uniform growth rate across the cities.

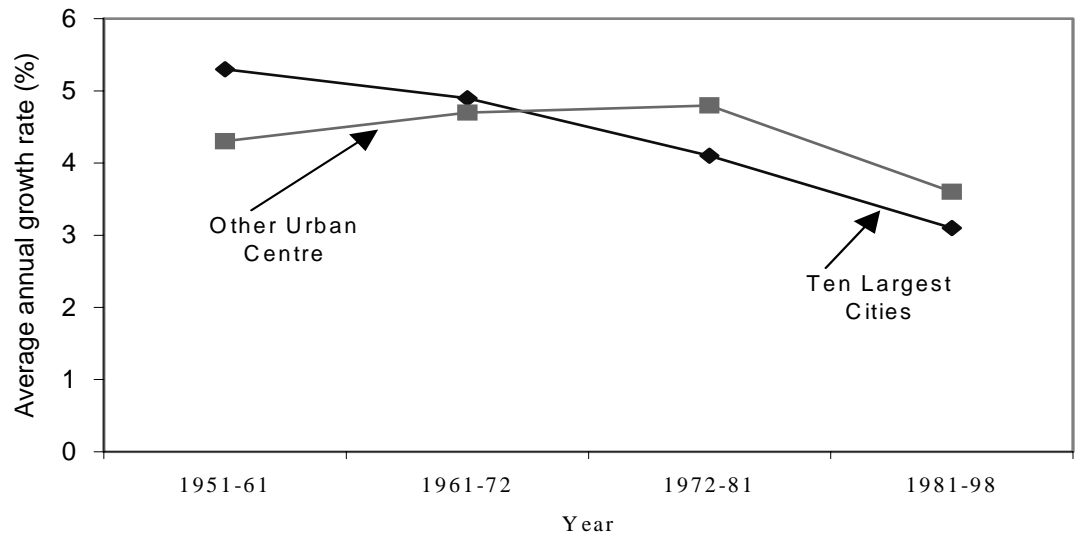

Fig. 1. Intercensal Annual Growth Rate of Ten Largest Cities and other Urban Centres (Excluding 10 Largest Cities) 1951-98. 


\section{PACE (OR TEMPO) OF URBANISATION}

Tempo or pace of urbanisation is commonly used to understand the urbanisation pattern of a country [UN (1993)]. It is usually measured by two ways: first by calculating the annual rate of change in percent share of urban population (see footnote (a) to Table 3). Second, it is measured by the difference between the growth rate of the urban population and that of the rural population, commonly referred as the urban-rural growth difference (URGD). The second measure, URGD, is considered better because it is less dependent on the urbanisation level itself [Pernia (1991)]. It also takes into account the distributional shifts in population between the urban and rural areas [UN (1993)]. Both measures of pace of urbanisation are reported in Table 3. The two measures, however, show the same pattern of urbanisation. In the chronological order, the tempo of urbanisation was highest during the 1950s. It declined dramatically during the 1960s. The pace of urbanisation rose after 1972, though the rise was small as compared to the 1951-61 period. It, according to the 1998 census data, declined to its lowest level in the 1990s (Table 3).

This recent decline in the pace of urbanisation is contrary to the results of Butt's study, which showed an increase in the pace for the period of 1991-93 (see figures in parentheses in Column 7 of Table 3). The main reason for this contradiction is that the average annual urban growth rate shown in Butt's study for the period of 1981-93 was 4.8 percent and the urban population share in the total population in his study was shown as 35 percent [Butt (1996)]. These two figures particularly the growth rate does not match with the 1998 census data.

Table 3 shows that the tempo of urbanisation in all provinces but Balochistan was highest during the 1950s, falling during 1960s, and rose again during 1970s. The pace of urbanisation increased in Balochistan during the 1980s and 1990s, while it decreased in other provinces. This decline was marginal for Sindh. It, however, was substantial for Punjab and NWFP. More importantly, it appears that, like the annual urban growth rate, there is an increasing convergence across provinces in terms of the tempo of urbanisation.

Abbasi (1987); Rukanuddin (1989) and Butt (1996) have explored reasons for large variations in the tempo of urbanisation during 1951-81. These studies attributed the rapid pace of urbanisation during the 1950s primarily to the resettlement pattern of Muslim refugees from India and higher net in-migration to the urban centres of the country. The decline in the pace of urbanisation during 1960s was mainly due to rapid decline in the net in-migration rate to the urban areas. Rising pace of urbanisation during 1970s was attributed to the relatively high natural increase as experienced by the urban population and the Middle East migration. The phenomenon of high urban fertility was supported by the evidence that marital fertility rate in urban areas was higher than in rural areas during the 1970s [Kiani and Siyal (1991)]. 
Table 3

Tempo of Urbanisation by Province, 1951-1998

\begin{tabular}{|c|c|c|c|c|c|c|c|c|}
\hline \multirow[b]{2}{*}{ Province } & \multicolumn{2}{|c|}{ 1951-61 } & \multicolumn{2}{|c|}{ 1961-72 } & \multicolumn{2}{|c|}{$1972-81$} & \multicolumn{2}{|c|}{ 1981-98 } \\
\hline & (a) & (b) & (a) & (b) & (a) & (b) & (a) & (b) \\
\hline Pakistan & 23.5 & 3.0 & 10.4 & 1.3 & 12.8 & 2.2 & $8.2(17.5)^{*}$ & 1.3 \\
\hline Punjab & 20.8 & 2.7 & 11.2 & 1.2 & 17.0 & 2.2 & 7.4 (13.1) & 1.1 \\
\hline Sindh & 27.5 & 4.2 & 5.5 & 0.7 & 8.8 & 1.7 & 7.1 (12.5) & 1.3 \\
\hline NWFP & 18.3 & 2.1 & 6.9 & 0.4 & 20.4 & 1.2 & $6.6(15.5)$ & 0.9 \\
\hline Balochistan & 34.2 & 4.0 & -2.1 & -0.7 & 1.5 & -0.2 & 23.6 (11.9) & 3.1 \\
\hline
\end{tabular}

Source: Abbasi (1987); Butt (1996); Pakistan (1998).

* Figures in parentheses are the tempo of urbanisation calculated by Butt (1996) for the period of 1991-93.

Note: Islamabad and FATA are included in the country level figures. But they are not included in the provincial figures. The tempo of urbanisation (a) for Islamabad for the period of 1981-98 was 5.2 .

(a) Tempo of urbanisation refers to annual rate of change in percent share of urban population and is calculated as:

$$
\mathrm{T}=\frac{2\left(P_{u}^{t+n}-P_{u}^{t}\right.}{n\left(P_{u}^{t+n}+P_{u}^{t}\right.} * 1000
$$

Where

$$
\begin{aligned}
& P_{u}{ }^{t}=\text { level of urbanisation at time } t . \\
& P_{u}{ }^{t+n}=\text { level of urbanisation at time } t+n . \\
& n=\text { interval between } t+t+n .
\end{aligned}
$$

(b) Tempo of urbanisation refers to the urban rural growth difference.

The question is what are the reasons for slackening the tempo of urbanisation during the 1980s and 1990s? Some of the changes in urban population might be due to the definitional changes of 'urban'. As noted earlier, some communities adjacent to large cities might have been counted as rural in the 1998 census as compared to 1981 census when they were considered urban due to updating of delimitation of areas [Jillani (1998)]. For example, the 1998 census indicates that the share of urban population in the total population of Lahore districts declined from 84 percent in 1981 to 82 percent in 1998. It is likely that some communities of Lahore districts that were considered urban in 1981 were reclassified as rural in 1998.

There are some recent indications that total martial fertility rate, which in the 1970s was higher in urban areas than in rural areas, has reversed in the 1990s. Urban families have at least one child less than their rural counterparts [Hakim et al. (1998)]. This pattern is likely to have depressed to some extent both the growth of urban population and pace of urbanisation. 
There is a possibility that net in-migration rate to urban centres which, according to Abbasi (1987), declined during 1972-81, declined further during the 1980s and 1990s. This decline may be due to the deteriorating law and order situation, ethnic strife and sectarian tension in different urban centres of the country. Among other factors, the worsening law and order situation have affected adversely the growth of manufacturing sector, which declined from 11 percent in 1987-88 to -2.3 percent in 1996-97 [Pakistan (1998a)]. This in turn has reduced the capacity of manufacturing sector to absorb rural migrants. The share of manufacturing sector in total employment also declined from 14 percent in 1987-88 to about 10 percent in the early 1990s.

Finally, the settlement of illegal immigrants in large urban centres might have depressed the movement of rural people to these centres. In the late 1990s, about 2 million illegal immigrants mostly Bangladeshis and Burmese were found only in Karachi. Their share in the total population of the city in 1998 was about 17 percent. These immigrants were working in fishery and service sectors at relatively low wages [Arif and Irfan (1997)].

\section{COMPONENTS OF URBAN GROWTH}

There are three components of urban population growth: net natural increase; net rural-urban migration; and net reclassification which is done either through the annexation of town into urban areas or the transformation of formerly rural areas into urban. According to Jones (1991), international migration can be a fourth factor of considerable importance in some countries, for example, Hong Kong. In the case of Pakistan, it can also be important because of both settlement pattern of Afghan refugees and the influx of illegal immigrants to large urban centres particularly Karachi. But data are not available from the recent census to separate out the contribution of immigration to urban growth.

The contributions made by the three different components (natural increase, reclassification and internal migration) to urban growth during 1981-98 are reported in Table 4. Decomposition of urban population growth for the 1972-81 period is also reported in the table. The trend over time shows that for both periods, 1972-81 and 1981-1998, urban population grew primarily because of natural increase. However, its role was more dominant in the 1970s than in the 1980s and 1990s. It might be due to a decline in urban marital fertility rate, which declined substantially from 8.1 in the mid-1970s to 5.7 in the early 1990s [Kiyani and Siyal (1991); Hakim et al. (1998)].

The role of reclassification in the urban growth was less important during the 1970s than its role in the 1980s and 1990s. During the latter period, the contribution accounted by the reclassification was about 10 percent. The share of internal migration in urban growth was similar for the two periods, 1972-81 and 1981-98 (Table 4). Variations in the role of each component of urban growth are apparent across the different regions during 1981-98. The dominance of natural increase as a factor of

growth is found in all regions, except Islamabad where internal migration was more

important than other two factors of urban growth. Internal migration also contributed

significantly in the growth of urban population of Balochistan and Sindh (Table 4). 
Table 4

Components of Urban Growth by Province, 1972-1998

\begin{tabular}{llcccc}
\hline \multirow{2}{*}{ Period } & Region & Natural Increase & Reclassification* & $\begin{array}{c}\text { Internal } \\
\text { Migration }\end{array}$ & Total Increase \\
\hline $1981-98$ & Pakistan & 70.3 & 9.7 & 20.1 & 100 \\
& Punjab & 74.2 & 11.3 & 14.5 & 100 \\
& Sindh & 70.6 & 4.5 & 24.8 & 100 \\
& NWFP & 70.0 & 20.9 & 9.1 & 100 \\
& Balochistan & 43.7 & 18.4 & 37.9 & 100 \\
& Islamabad & 35.1 & - & 64.9 & 100 \\
\hline
\end{tabular}

Source: Pakistan (1989, 1998).

*The share of reclassification in urban growth is computed by taking into account only those formerly rural areas that were transformed into urban during 1981-98. Information on annexation of towns into pre-existed urban areas is not available. This annexation can affect the share of reclassification in the urban growth.

\section{CHARACTERISTICS OF URBAN SYSTEM}

There has been a considerable increase in the number of urban places: from 388 in 1981 to 468 in 1998 (Table 5). ${ }^{9}$ Of these, 7 cities (Karachi, Lahore, Faisalabad, Rawalpindi, Multan, Hyderabad and Gujranwala) had a population greater than 1 million. Their share in the total urban population was 50 percent in 1998 compared to only 39 percent in 1981. This significant rise is mainly due to an increase in the number of cities with more than 1 million population: from only 3 (Karachi, Lahore and Faisalabad) in 1981 to 7 in 1998 . The share of cities in category II $(500,000-999,999)$ decreased from about 15 percent in 1981 to 5 percent in 1998. Number of cities in this category decreased as well from 5 in 1981 to 3 (Peshawar, Quetta and Islamabad) in 1998 (Table 5). The share of medium-sized cities, categories III and IV (100,000499,999) increased from 14 percent in 1981 to about 18 percent in 1998. The proportion of urban population living in small towns, categories $\mathrm{V}(<100,000)$ declined from 32 percent in 1981 to 27 percent in 1998. These statistics clearly indicate the concentration of urban population in the few large cities. This concentration was further confirmed by urban primacy and Gini concentration ratios (Table 6).

However, the annual growth of cities according to their sizes presents to some extent a different picture (Table 5). The annual growth rate of the 7 major cities in category I was 3.3 percent for the period of 1981-98, while for the category II it was 4.1 percent. However, the growth rate for the latter was influenced heavily by the growth of

${ }^{9}$ In the present analysis, cantonments are not counted as separate urban settlements. They are merged with the cities where they are located. Moreover, in the 1998 census, within a large city, such as Karachi and Hyderabad, several urban localities have been shown. In the present analysis, all urban localities of a large city are considered as one urban settlement. 
Table 5

Average Annual Growth Rate of Cities and Share of Natural Increase in Urban Growth, By Size of the Cities, 1981-98

\begin{tabular}{|c|c|c|c|c|c|c|c|}
\hline \multirow[b]{2}{*}{ Categories } & \multirow[t]{2}{*}{$\begin{array}{l}\text { Size of Cities } \\
\text { (Persons) }\end{array}$} & \multicolumn{2}{|c|}{$\begin{array}{c}\text { Number of } \\
\text { Cities }\end{array}$} & \multicolumn{2}{|c|}{$\begin{array}{c}\text { \% Share in } \\
\text { Urban } \\
\text { Population }\end{array}$} & \multirow[t]{2}{*}{$\begin{array}{l}\text { Average Annual } \\
\text { Growth Rate } \\
\text { (1981-98) }\end{array}$} & \multirow[t]{2}{*}{$\begin{array}{c}\text { \% Share of } \\
\text { Natural } \\
\text { Increase }\end{array}$} \\
\hline & & 1981 & 1998 & 1981 & 1998 & & \\
\hline $\mathrm{I}$ & $\geq$ million & 3 & 7 & 38.9 & 50.1 & 3.3 & 74.0 \\
\hline II & $500,000-999,999$ & 5 & 3 & 14.5 & 4.9 & 4.1 & 62.1 \\
\hline III & $200,000-499,999$ & 4 & 13 & 4.5 & 9.1 & 3.1 & 81.1 \\
\hline IV & $100,000-199,999$ & 17 & 27 & 9.9 & 8.6 & 3.2 & 76.2 \\
\hline $\mathrm{V}$ & $<100,000$ & 359 & 418 & 32.2 & 27.3 & 3.7 & 61.9 \\
\hline All & & 388 & 468 & 100.0 & 100.0 & 3.5 & 70.3 \\
\hline
\end{tabular}

Source: Pakistan (1984, 1998).

Note: In parentheses are the shares of urban localities in the 1981 census.

Table 6

Percentage of Urban Population in the Largest City of the Country (Karachi), Index of Primacy and Gini Concentration Ratios, 1951-1998

\begin{tabular}{lccc}
\hline Year & $\begin{array}{c}\text { Share of Karachi in Urban } \\
\text { Population (\%) }\end{array}$ & Index of Primacy & $\begin{array}{c}\text { Gini Concentration } \\
\text { Ratios }\end{array}$ \\
\hline 1951 & 18.0 & 0.81 & 0.71 \\
1961 & 19.4 & 0.89 & 0.75 \\
1972 & 21.2 & 0.97 & 0.75 \\
1981 & 21.9 & 1.07 & 0.75 \\
1998 & 21.8 & 1.10 & 0.75 \\
\hline
\end{tabular}

Source: Butt (1996); Pakistan (1998).

Note: Index of primacy is the ratio of the population of Karachi to the cumulated population of the next three largest cities, Lahore, Faisalabad and Rawalpindi.

Islamabad and Quetta. Between 1981 and 1998 the medium-sized towns (categories III and IV) grew annually at a rate of more than 3 percent. The growth rate at which the small towns (categories V) grew annually during this period was 3.7 percent, which is higher than the rate of any other category shown in Table 5, except the rate of cities in category II. The last column of Table 5 reveals that natural increase as component of urban growth was more important in cities included in the categories I, III and IV than in cities included in other classes. The growth of Islamabad, Quetta and Peshawar (categories II) was probably relatively more influenced by internal migration. In the growth of small towns reclassification seems to have played a major role. ${ }^{10}$ To

${ }^{10}$ During the 1981-98 period, more than 90 rural settlements were reclassified as urban. All of these settlements had a population of less than 100,000 in 1998, thus included in the last row in Table 5. 
summarise, it is true that urban population is still concentrated in large urban centres, but there is an increasing convergence in urban growth across the large, medium and small towns/cities. De-concentration process has probably begun.

\section{SUMMARY AND POLICY IMPLICATIONS}

The main objective of this study was to examine the trends and patterns of urbanisation in Pakistan by utilising primarily the provisional results of the 1998 population census. While information given in these results was very limited, determinants and consequences of urbanisation could not be included in the analysis. In absolute terms, the population living in urban areas has increased substantially during the last 50 years. The urban population in 1998 exceeded the total population of the country at the time of Independence. The degree of urbanisation has also increased from a low level of 18 percent in 1951 to a moderate level of 33 percent in 1998. But the average annual growth rate of urban population declined monitically from 4.9 percent during 1951-61 to 3.5 percent for the period of 1981-98. This declined was experienced by all four provinces. Urban population of three provinces, Punjab, Sindh and NWFP grew during the 1980s and 1990s at about the same rate (3.5 percent per annum).

The tempo of urbanisation also declined substantially during 1981-98. This decline can be attributed to the deteriorating law and order situation, illegal immigration, a slow down of rural to urban migration and reduction in urban marital fertility. With respect to the components of urban growth, natural increase was the main contributor, followed by internal migration and reclassification. The role of internal migration was relatively more important in the growth of both Islamabad and Balochistan. This assessment of each of the components of urban growth suggests the importance of adopting measures to regulate fertility to bring about a more balanced distribution of the urban population across regions. There is a need to launch a study to investigate the nature and socio-economic effects of internal migration, particularly on Balochistan.

Although the share of Karachi in total urban population has stabilised, still every fifth urban dweller of the country live in this city. There was no change in the index of primacy during the last two and half decades. Urban population continues to concentrate in major urban centres of the country. However, this study shows that small and medium-sized cities/towns have also grown rapidly during the last two decades.

In response to the process of urbanisation, the policies adopted by the government of Pakistan seem to be in a right direction. In the Fourth Year Plan (1970-75) the concentration of urban population in few large cities was first time officially realised, and the growth of these cities was termed as 'uncontrolled' and 
The Pakistan Development Review

37 : 4 Part II (Winter 1998) pp. 37:4, 507-522

'unbalanced'. The next plan (1978-83) developed strategies to accelerate the growth of small and medium-sized towns by upgrading their urban infrastructure. The subsequent three plans, sixth, seventh and eighth, followed this strategy with an additional emphasis on rural development. These efforts and policies seem to have exerted some influence on the directions of urbanisation, which have shifted to some extent to medium-sized cities. There is an urgent need to have an integrated national urbanisation policy, particularly for the formation of an urban management framework for small and middle-sized cities to maximise the country’s rural development potential.

\section{REFERENCES}

Abbasi, N. (1987) Urbanisation in Pakistan 1951-81. Islamabad: Pakistan Institute of Development Economics. (Research Report Series No. 152.)

Arif, G. M., and M. Irfan (1997) Return migration and occupational change: the case of Pakistani migrants returned from Middle East. The Pakistan Development Review 36:1 1-37.

Burki, S. J. (1973) Pakistan: A Demographic Report. Population Bulletin 29:4.

Butt, M. S. (1996) Prospects of Pakistan Urbanisation. Pakistan Economic and Social Review 34:2 155-178.

Ertur, O. (1994) The Need for a National Urbanisation Policy in Nepal. Asia-Pacific Population Journal 9:3 19-36.

Hakim, et al. (1998) Effects of Rapid Population Growth on Social and Economic Development in Pakistan. Islamabad: The National Institute of Population Studies.

Helbock, R. W. (1975) Differential Urban Growth and Distance Considerations in Domestic Migration Flows in Pakistan. The Pakistan Development Review 14:1 53-84.

Jillani, M. S. (1998) Measuring the Urban Population. The News, August 17-18, 1998.

Jones, G. W. (1991) Urbanisation Issues in the Asia-Pacific Region. Asian-Pacific Economic Literature 5:2 5-33.

Khan, A. (1996) Urbanisation and its Impact on Rural-urban Economic Integration in TWC's: The Case Study of Peshawar, NWFP. Pakistan, Journal of Rural Development and Administration 28:1 130-158.

Kiani, F. M., and H. B. Siyal (1991) Dimensions of urban growth in Pakistan. The Pakistan Development Review 30:4.

Pakistan, Government of (1951) Population Census of Pakistan 1951, Vol. 3. Karachi: Census Organisation. 
Pakistan, Government of (1984) 1981 Census Report of Pakistan, Punjab, Sindh, NWFP and Balochistan. Islamabad: Statistics Division, Population Census Organisation.

Pakistan, Government of (1989) Monograph on Migration and Urbanisation. Islamabad: Statistics Division, Population Census Organisation.

Pakistan, Government of (1998) Population and Housing Census of Pakistan 1998: Provisional Results. Islamabad: Statistics Division, Population Census Organisation.

Pakistan, Government of (1998a) Statistical Supplement 1997-98. Islamabad: Finance Division, Economic Affairs Wing.

Pakistan, Government of (n.d.) Population Census of Pakistan 1961, Vol. 3. Karachi: Census Organisation.

Pakistan, Government of (n.d.) Population Census of Pakistan 1972, Statistical reports for Pakistan, Punjab, Sindh, NWFP and Balochistan. Islamabad, Statistics Division, Population Census Organisation

Pernia, E. M. (1991) Some aspects of urbanisation and the environment in South Asia. Asian Development Bank, Economic and Development Resource Centre. (Report No. 54.)

Rukanuddin, A. R. (1989) Population Distribution, Migration, Urbanisation and Squatter Settlements Programme in Pakistan, Paper contributed to the International Workshop on Urbanisation and Population Distribution Policies in Asia, held at Population Institute, East-West Centre, Honolulu, Hawaii, March 27-31.

United Nations (1993) Urbanisation and Socio-economic Development in Asia and Pacific. New York: Economic and Social Commission for Asia and the Pacific. (Asia Population Studies Series No. 122.) 